\title{
Estado federal e poder municipal
}

\author{
André Carlos da Silva ${ }^{1}$
}

\section{Resumo}

O objetivo deste artigo é analisar a questão da autonomia do município no Estado federal brasileiro. Para desincumbir-se desse objetivo, o texto está estruturado em quatro capítulos. Parte-se da panorâmica do desenvolvimento do município no contexto do federalismo brasileiro, para adentrar na análise das conseqüências do Fundo de Participação dos Municípios para a simetria municipal, bem como da distribuição de competência segundo a Constituição Federal chegando à divergência doutrinária sobre a participação do município no sistema federal nacional, a fim de concluir que não obstante a Constituição Federal de 1988 tenha alargado o campo de autonomia dos municípios, a dubiedade da expressão "assunto de interesse local", associada com a natureza centralizadora do federalismo brasileiro, tem impedido o desenvolvimento do Município nessa área, que é tão relevante para sedimentar a sua autonomia.

Palavras-chave: Município. Federalismo municipal. Distribuição de competência.

\section{Introdução}

O tema do presente artigo é o Federalismo brasileiro, em especial, a presença do Município compondo esse sistema federativo.

Diferentemente de muitas federações, a brasileira, assim como a belga, é um sistema de três níveis: União, Estados e Municípios. Se, contudo, considerar-se o Distrito Federal, o Estado Federal brasileiro alcança a composição de quatro níveis. No Brasil, os municípios foram incorporados, juntamente com os estados, como partes integrantes da federação, com a Constituição Federal de 1988.

\footnotetext{
${ }^{1}$ Advogado. Mestre em Direito pelo Centro Universitário de Brasília. Email: andcarlos@ uol.com.br.
} 
Assim, a Constituição Federal de 1988 gerou um novo ordenamento federativo. Os constituintes não só estabeleceram as bases do Estado democrático como também instituíram um novo "pacto federativo". Em quase todas as constituições (exceto na Carta de 1937), os municípios foram definidos como organizações políticas autônomas. Contudo, somente a Constituição de 1988 atribuiu uma considerável autonomia aos municípios, conferindo-lhes o status de ente federativo.

Para desincumbir-se desse objetivo, o texto está estruturado em quatro capítulos principais. O primeiro - O município nas constituições brasileiras - se ocupa em registrar, de forma panorâmica, o desenvolvimento do Município no contexto da estrutura do Estado brasileiro, desde a inauguração do nosso Estado federal até o presente momento, com a promulgação da Constituição Federal de 1988. O segundo - O federalismo municipal assimétrico - procura demonstrar que a tentativa federal de uniformização, por meio do Fundo de Participação dos Municípios, trouxe mais assimetria do que simetria no contexto municipal. O terceiro - A distribuição do poder - dedica-se ao tema da distribuição de competência para o município, na forma estabelecida na Constituição Federal. O último - O município como ente federativo- enfrenta o tema, ainda controvertido no ambiente doutrinário brasileiro, a respeito de ser ou não o município participante do sistema federal nacional.

Conta ainda o trabalho com esta Introdução e uma Conclusão com considerações sobre o tema em foco.

\section{Município nas constituições brasileiras}

O município, na condição de unidade político-administrativa, já ocupava um lugar de destaque no processo de expansão do Império Romano, por ocasião da República. Se, de um lado, os vencidos ficavam sujeitos às leis romanas, de outro, eram-lhes concedidas algumas prerrogativas, tais como: alguns direitos privados e o direito de eleger seus governantes para dirigir a própria cidade. As cidades que alcançavam essa posição no Império Romano eram consideradas municípios².

\footnotetext{
${ }^{2}$ MEIRELLES, Hely Lopes. Direito municipal brasileiro. 14. ed. atual. por Márcio Schneider Reis e Edgard Neves da Silva. São Paulo: Malheiros, 2006. p. 33.
} 
Por isso, embora se reconheça, em tempos mais remotos, a existência de agrupamentos humanos, famílias, aldeias e tribos, o título de município somente veio a ser concedido a algumas cidades dominadas pelos exércitos de Roma ${ }^{3}$.

No apagar das luzes do século XV, quando se descobriu o Brasil, os portugueses trouxeram a instituição municipal para o Brasil-Colônia. Em 22 de janeiro de 1532, é fundado, por Martim Afonso, o primeiro município brasileiro: São Vicente. Daí se dizer que, entre nós, o município nasceu antes do Estado e que, portanto, é a base e fundamento de nossa nação ${ }^{4}$.

Desde a sua origem, o município surge sob o signo da constituição do poder local, com a vocação para atender as demandas das comunidades que lhe são próximas. É, pois, o locus mais próximo entre o aparelho estatal e o cidadão. Portanto, lugar onde as demandas sociais chegam com menos intermediários ao conhecimento do Poder Público. Sob essa perspectiva, o município se apresenta como um lugar onde reside a força dos povos livres ${ }^{5}$. As pessoas não se inserem imediatamente no Estado Federal. Antes, ordenam-se nas comunidades a que pertencem, sendo uma delas o município. Nesse contexto, o município é uma comunidade natural, necessária e sociológica, e não uma realidade puramente jurídica. Por isso, o papel do Estado é de reconhecer e de admitir e não de criar, visto que, na ordem do ser e do tempo, o município precede o próprio Estado ${ }^{6}$.

A trajetória do município nas Constituições brasileiras, a partir da instalação, entre nós, do Estado Federal, conforme se verá adiante, é marcada por quatro pontos principais, a saber: a) um significativo aumento da relevância do município no Estado Federal brasileiro; b) um incontestável aumento numérico do município no Estado Federal brasileiro; c) um aumento quantitativo

${ }^{3}$ CASTRO, José Nilo de. Direito municipal positivo. 6. ed. rev. e atual. Belo Horizonte: Del Rey, 2006. p. 6.

${ }^{4}$ CASTRO, José Nilo de. Direito municipal positivo. 6. ed. rev. e atual. Belo Horizonte: Del Rey, 2006. p. 11 - 12.

${ }^{5}$ TOCQUEVILLE, Aléxis de. A democracia na América. Tradução de Eduardo Brandão. São Paulo: M. Fontes, 2005. p. 75-80. Livro 1

${ }^{6}$ HERRERA, Oscar Rebolledo. El marco jurídico del município en un contexto federalizado. Biblioteca Jurídica Virtual. Instituto de Investigaciones Jurídicas. El município em México y en el mundo. In: CONGRESO INTERNACIONAL DE DERECHO MUNICIPAL, 1. 2005, p. 379-388. 
e qualitativo das competências do município, bem como um progressivo processo de autonomia até culminar com o ente que compõe a federação; e d) a oscilação do pêndulo de estadualização para federalização do município.

\subsection{Constituição Federal de 1891}

A Constituição de 1891 confirma o sistema federal brasileiro. A federação foi criada a partir das 20 (vinte) províncias herdadas do sistema unitário, contando hoje com 27 Estados, o Distrito Federal e mais de $5.600^{7}$ municípios.

O art. 2. ${ }^{\circ}$ da Constituição Federal de 1891 dispunha que "Cada uma das antigas províncias formará um Estado, e o antigo município neutro constituirá o Distrito Federal, continuando a ser a capital da União, enquanto não se der execução ao disposto no artigo seguinte." Por sua vez, o art. 68. ' do mesmo texto Constitucional estabelecia que "Os Estados organizar-se-ão de forma que fique assegurada a autonomia dos municípios, em tudo quanto respeite ao seu peculiar interesse".

Firmados nesses comandos constitucionais, os Estados esgotaram, na amplitude de sua autonomia, a organização municipal, submetendo o governo local aos rigores do controle hierárquico. Os Estados fundaram suas ações organizativas concentrados no verbo "organizar-se-ão" e deixaram de observar o conteúdo da expressão, também constitucional, “assegurada a autonomia dos municípios”. Assim, teve lugar a chamada "organização vertical do Município".

Desde a inauguração do Estado Federal no Brasil, suscitou-se a dúvida a respeito da possibilidade da existência de uma organização diferenciada entre os

\footnotetext{
${ }^{7}$ Essa, contudo, não é uma quantidade exagerada de Municípios. Conforme informação de CASTRO, José Nilo de. Direito municipal positivo. 6. ed. rev. e atual. Belo Horizonte: Del Rey, 2006. p. 10, "Em 1 de janeiro de 1995, a França tinha 36.627 Municípios; Espanha, 8.082 e Itália, 8.074 Municípios (Cf. Les collectinités de l'Union Européenne, p. 16-18). Esse número continua o mesmo, na atualidade." No mesmo sentido, HORTA, Raul Machado. Direito constitucional. 2. ed. rev. atual. e amp. Belo Horizonte: Del Rey, 1999. p. 626, citando William Vermon Holloway, informa que "a pluralidade organizatória da estrutura local norte-americana, por exemplo, que abrange na sua diversificação Condados, Cidades, Municipalidades, Distritos Escolares, Distritos Especiais. Essas chamadas entidades de governo local, atingem a impressionante cifra de 155.067 unidades dentro da Federação norte-americana."
} 
entes da federação ${ }^{8}$. Paraíba e Minas Gerais tentaram se organizar por meio de distritos especiais e cantões, respectivamente, o que não veio a efetivar-se ${ }^{9}$.

Conquanto trate-se de casos isolados, o Rio Grande do Sul e Santa Catarina, no entanto, obtiveram êxito na criação da chamada "comunidade jurídica descentralizada”, um ordenamento jurídico parcial, responsável pela expedição de normas dotadas de validade na circunscrição local.

As controvérsias hermenêuticas em torno do art. $68 .^{\circ}$ da Constituição Federal de 1891, as tentativas de organização municipal diferenciada e as experiências de descentralização por parte do Rio Grande do Sul e de Santa Catarina criaram o ambiente propício para se iniciar um processo de questionamentos nos ambiente político, doutrinário e também no Supremo Tribunal Federal. O objetivo era desvendar se a autonomia municipal seria ou não um princípio constitucional da União.

Venceu a corrente que defendia que a autonomia municipal era um princípio constitucional da União. A materialização desse pensamento aparece na Reforma Constitucional de 1926, que incluiu a autonomia municipal entre os princípios constitucionais da União (art. 6., II, alínea “f”), cuja eficácia ficaria assegurada pelo mecanismo drástico da intervenção federal da União no Estado.

A Emenda Constitucional, de 3 de setembro de 1926, alterou vários dispositivos. Em relação aos municípios, merece destaque a alteração efetivada no art. $6^{\circ}$, cujo inciso II, alínea "f", dispõe o seguinte:

Art. $6 .^{\circ} \mathrm{O}$ Governo federal não poderá intervir em negócios peculiares aos Estados, salvo:

$[\ldots]$

II - para assegurar a integridade nacional e o respeito aos seguintes princípios constitucionais:

$[\ldots]$

f) a autonomia dos municípios.

\footnotetext{
${ }^{8}$ MONTORO, 1945 apud CORRALO, Giovani da Silva. Município: autonomia na federação brasileira. Curitiba: Juruá, 2006. p. 75.

${ }^{9}$ CORRALO, Giovani da Silva. Município: autonomia na federação brasileira. Curitiba: Juruá, 2006. p. 75.
} 
A intervenção federal no Estado, para proteger a autonomia municipal, deslocava para o domínio dos órgãos da União a tarefa de interpretar a autonomia municipal pelo preenchimento federal do campo indefinido da norma constitucional. Assim, a autonomia local passaria a comportar interpretação federal e não mais a interpretação que lhe desse o Estado-Membro no exercício do poder de organização do município.

Nesse contexto, a qualificação da autonomia municipal como princípio constitucional da União representa uma limitação à plenitude da autonomia do Estado-Membro e traduzia claro rompimento com a concepção ortodoxa do federalismo republicano de 1891. De qualquer modo, o pêndulo deslocou-se do EstadoMembro para a União. Mas, o princípio da centralização organizativa permaneceu ainda mais forte, visto que, após a reforma constitucional de 1926, a União mesma voltava os seus tentáculos para o município.

\subsection{Constituição Federal de 1934}

Sob o ponto de vista do processo de emancipação do município da tutela organizatória do Estado-Membro, a Constituição de 1934 representou um significativo avanço. O texto dessa Constituição espelha a convicção de que não bastaria ao município a autonomia política, vinculada a escolha eletiva dos representantes locais, conforme preceituava a Constituição de 1891, mas se impunha acrescentarlhe a autonomia financeira, as receitas próprias, de modo a alargar a substância da autonomia. Nesse contexto, assim estabelece o $\$ 2^{\circ}$ do art. $8^{\circ}$ da Constituição de 1934: “art. $8^{\circ}, \$ 2^{\circ}$. O imposto de indústrias e profissões será lançado pelo Estado e arrecadado por este e pelo Município em partes iguais".

Ainda o parágrafo único do art. $10^{\circ}$, assim dispunha:

Art. 10, parágrafo único. A arrecadação dos impostos a que se refere o n. VII será feita pelos Estados, que entregarão, dentro do primeiro trimestre do exercício seguinte, trinta por cento à União, e vinte por cento aos Municípios de onde tenham provindo. Se o Estado faltar ao pagamento das quotas devidas à União ou aos Municípios, o lançamento e a arrecadação passarão a ser feitos pelo Governo Federal, que atribuirá, nesse caso, trinta por cento ao Estado e vinte por cento aos Municípios. 
Manteve, ainda, essa Carta Política a proteção do Município a cargo da União, por meio da possibilidade de uso da cláusula de intervenção nos negócios do Estado nos casos de preservação do princípio da autonomia municipal (art. $12^{\circ}$, inciso V, c/c o art. 7º inciso I, alínea “d”).

Nesse contexto, a inovação da Constituição de 1934 alcança um tríplice conteúdo: autonomia política, autonomia financeiro-tributária e autonomia administrativa.

Em termos de vedação (arts. $17^{\circ}$ e $19^{\circ}$ ), o Município é equiparado à União, aos Estados e ao Distrito Federal.

$\mathrm{O}$ art. $13^{\circ}$ demarca o conteúdo material da autonomia do Município.

Art. $13^{\circ}$ Os Municípios serão organizados de forma que lhes fique assegurada a autonomia em tudo quanto respeite ao seu peculiar interesse, e especialmente:

I - a eletividade do Prefeito e dos Vereadores da Câmara Municipal, podendo aquele ser eleito por esta;

II - a decretação dos seus impostos e taxas, e a arrecadação e aplicação das suas rendas;

III - a organização dos serviços de sua competência.

$\$ 1^{\circ}$. O Prefeito poderá ser de nomeação do governo do Estado no município da Capital e nas estâncias hidrominerais.

$\$ 2^{\circ}$ Além daqueles de que participam, ex vi dos artigos $8^{\circ}, \S$ $2 .^{\circ}$ e 10 , parágrafo único, e dos que lhes forem transferidos pelo Estado pertencem aos Municípios:

I - o imposto de licenças;

II - os impostos predial e territorial urbanos, cobrado o primeiro sob a forma de décima ou de cédula de renda;

III - o imposto sobre diversões públicas;

IV - o imposto cedular sobre a renda de imóveis rurais;

$\mathrm{V}$ - as taxas sobre serviços municipais.

Há mesmo quem defenda, com certo grau de acerto, que a Constituição de 1934 foi a que mais desceu a minúcias com o objetivo de preservar o princípio 
da autonomia municipa ${ }^{10}$. Apesar disso, deve ser notado que alguns passos em relação à democracia representativa precisavam ser dados para a consagração do princípio da autonomia municipal. Isso porque, conforme se constata do dispositivo constitucional acima transcrito, a escolha do prefeito poderia estar a cargo da Câmara Municipal. De qualquer modo, os avanços entabulados pela Constituição de 1934 no tocante à autonomia municipal não passaram pelo crivo do processo de amadurecimento, dada a curta vigência desse texto constitucional.

\subsection{Constituição Federal de 1937}

A Constituição de 1937 inaugura um novo regime político, o chamado Estado Novo. No campo municipal, a autonomia política restou enfraquecida, visto que o Prefeito passou a ser de livre nomeação do Governador (art. 27º). O Presidente da República dispunha, solitariamente, do poder de intervir nos Estados para restabelecer a ordem e para administrá-lo. Com isso, teve lugar o regime de intervenção, que alcançou estados e municípios.

Assim, embora a Constituição de 1937 tenha mantido no texto a federação e o status do Município (arts. $25^{\circ}-30^{\circ} ; 35^{\circ}$ ), na condição de ente autônomo, foi uma manutenção apenas nominal. Na prática, sob o pálio do regime constitucional de 1937, o Brasil se transformou em um Estado unitário. O retrocesso alcançou profundidade tal que os municípios se tornaram menos autônomos nesse período do que no período do centralismo imperial ${ }^{11}$.

\subsection{Constituição Federal de 1946}

Com a deposição do regime ditatorial brasileiro, ressurgiram as esperanças do ideal democrático. No que toca às municipalidades, a Constituição de 1946 deu nova vida ao Município, devolvendo-lhe as prerrogativas constitucionais da Constituição de $1934\left(\operatorname{arts} .15^{\circ}, 20^{\circ}, 21^{\circ}, 22^{\circ}, 23 .^{\circ}, 28^{\circ}, 29^{\circ}, 30^{\circ}, 31^{\circ}, 32^{\circ} \mathrm{e}\right.$

${ }^{10}$ MEIRELLES, Hely Lopes. Direito municipal brasileiro. 14. ed. atual. por Márcio Schneider Reis e Edgard Neves da Silva. São Paulo: Malheiros, 2006. p. 40.

${ }^{11}$ MEIRELLES, Hely Lopes. Direito municipal brasileiro. 14. ed. atual. por Márcio Schneider Reis e Edgard Neves da Silva. São Paulo: Malheiros, 2006. p. 41. 
$33^{\circ}$ ). Isso, contudo, não foi suficiente para afastar as influências do regime político anterior nessa matéria. Por várias vezes, o Supremo Tribunal Federal teve de exercer a defesa da autonomia municipal, tendo como fundamento o novo texto constitucional. A título de exemplo, serão apresentadas adiante três representações examinadas pela Suprema Corte.

A Constituição do Estado do Ceará, em seus artigos $34^{\circ}$ e $104^{\circ}$, autorizava a suspensão da execução de leis, posturas e atos da administração municipal e conferia à Assembléia Legislativa a competência para anular leis, resoluções e atos municipais, nos casos que indicava. Contra esses dispositivos, o Procurador Geral da República aviou a Representação n. 295 junto ao Supremo Tribunal Federal.

No exame a que procedeu, sob a relatoria do Ministro Cândido Motta Filho, o Supremo Tribunal Federal veio a declarar a inconstitucionalidade desses dois dispositivos da Constituição cearense. Em seu voto, o eminente Ministro deixou assentado que o Município dirige tudo que é do seu peculiar interesse, de sua administração, independente de qualquer intromissão tutelar. No que toca à anulação de atos normativos, somente ao Poder Judiciário compete apreciar a constitucionalidade de leis ou atos do Poder Público, porque a presunção de constitucionalidade é um princípio necessário à estabilidade do Estado de direito ${ }^{12}$.

No mesmo sentido, o art. $104^{\circ}$ da Constituição do Estado do Rio de Janeiro admitia a anulação de deliberações e de atos das Câmaras Municipais pela Assembleia Legislativa. Contra os termos desse dispositivo, o Procurador Geral da República ingressou com a Representação n. $314^{\circ}$ perante o Supremo Tribunal Federal, sustentando que essa norma de hierarquia superior estadual afrontava o princípio da autonomia municipal inserto na Constituição Federal.

Mais uma vez, o Supremo Tribunal Federal, em processo relatado pelo Ministro Lafayette de Andrada, acolheu os fundamentos expendidos pelo Procurador Geral da República e considerou inconstitucional o art. 104 da

${ }^{12}$ BRASIL. Supremo Tribunal Federal. Representação $n^{\circ}$ 95. Tribunal Pleno. Relator: Min. Cândido Mota Filho. Brasília, 02 de setembro de 1957. Disponível em: <www. stf.gov.br>. 
Constituição do Estado do Rio de Janeiro, reconhecendo, assim, a extensão do princípio da autonomia municipal consagrado na Constituição Federal de $1946^{13}$.

Por fim, o último exemplo refere-se ao art. $91^{\circ}$ da Constituição do Estado de Minas Gerais. O referido dispositivo previa o recurso, com efeito suspensivo, para o Tribunal de Contas ou para a Assembléia Legislativa, de decisão da Câmara Municipal que impusesse a perda do cargo do Prefeito.

O Procurador Geral da República protocolou no Supremo Tribunal Federal a Representação no 350, que foi relatada pelo Ministro Henrique D’Avila. No fundamento de seu voto, acolhido pelo Plenário, o Relator faz referência aos julgados semelhantes referentes às Constituições dos Estados do Rio de Janeiro e do Ceará para concluir no sentido de que os dispositivos questionados representam exorbitância insuportável ${ }^{14}$.

Nos três casos acima referidos, o fundamento comum da inconstitucionalidade assentou-se na defesa da autonomia municipal, incompatível com a tutela hierárquica de órgãos estaduais.

\subsection{Constituição Federal de 1967}

A Constituição de 1967 manteve muitas regras consagradas no texto da Constituição de 1946. Contudo, apresentou inovações: criou a competência do Município na Constituição Federal (arts. $13^{\circ}-16^{\circ}$; $19^{\circ}$ e $25^{\circ}$ ). No entanto, preservou, em parte, o princípio da ocupação do cargo de Prefeito vigente por ocasião da Constituição de 1937, na medida em que os Prefeitos das capitais, das estâncias hidrominerais e dos municípios declarados de interesse da segurança nacional por lei de iniciativa do Poder Executivo eram nomeados pelo Governador com prévia aprovação da Assembléia Legislativa ou do Presidente da República, conforme o caso (art. 15, $§ 1^{\circ}$, alíneas “a” e "b").

\footnotetext{
${ }^{13}$ BRASIL. Supremo Tribunal Federal. Representação $n^{\circ}$ 314. Tribunal Pleno. Relator: Min. Lafayette de Andrada. Brasília, 23 de setembro de 1957. Disponível em: <www. stf.gov.br>.

${ }^{14}$ BRASIL. Supremo Tribunal Federal. Representação nº 350. Tribunal Pleno. Relator: Min. Henrique D’Avila. Brasília, 26 de janeiro de 1959. Disponível em: <www.stf.gov.br>.
} 
Além disso, deu início ao movimento de alargamento da matéria de interesse municipal, o que influenciou negativamente na autonomia constitucional do EstadoMembro. Nesse contexto, retira da Constituição e das leis estaduais, para entregar à lei complementar federal, a competência para: a) estabelecer os requisitos mínimos de população, renda pública e a forma de consulta prévia às populações locais, para criação de novos municípios (art. 14º); b) dispor sobre a remuneração de Vereadores das capitais e dos municípios de população superior a cem mil habitantes (art. 16º,$\S$ $\left.2^{\circ}\right)$; e c) estabelecer o número máximo de Vereadores (art. 16º $\$ 5^{\circ}$ ).

A Emenda Constitucional n. 1 de 1969 manteve as prerrogativas da Constituição revista e aprofundou o movimento de dilatação da matéria municipal na Constituição Federal. Ocorreu, assim, a federalização dos temas municipais pela sua retirada da área das Constituições Estaduais e a sua conversão em temas da Constituição Federal e da legislação federal. Intensificou-se o controle da autonomia municipal na Constituição Federal, prevendo-se os instrumentos adequados.

\subsection{Constituição Federal de 1988}

A Constituição de 1988 continuou conferindo relevância aos municípios, sendo caracterizada pela ampliação da autonomia municipal e, sobretudo, pela conferência ao Município do status de ente integrante da federação.

A Federação tem sido marcada por políticas públicas federais que se impõem às instâncias subnacionais, mas que são aprovadas pelo Congresso Nacional e por limitações na capacidade de legislar sobre políticas próprias. Além do mais, poucas competências constitucionais exclusivas são alocadas aos estados e municípios.

Nas Constituições anteriores, as prerrogativas dos municípios estavam circunscritas ao governo próprio e à competência exclusiva, que correspondem ao mínimo para que uma entidade territorial tenha autonomia constitucional. Atualmente, foi-lhes reconhecido o poder de auto-organização, ao lado de governo próprio e competência exclusiva, e ainda com ampliação delas; de sorte que a Constituição criou verdadeiramente uma nova instituição municipal no Brasil. Não há mais a figura de prefeitos nomeados. Tornou-se plena, pois, a capacidade de autogoverno municipal entre nós. 
Nos termos dos artigos $29^{\circ}$ e $30^{\circ}$ da Constituição Federal, os municípios dispõem das seguintes capacidades: de auto-organização, de autogoverno, de autolegislação e de autoadministração. A isso, ajuntam-se a autonomia política, a autonomia financeira, a autonomia legislativa e a autonomia administrativa.

A partir de 1990, os governos locais passaram a ser os principais provedores dos serviços de saúde e de educação fundamental, a partir de regras e recursos federais, os quais visam garantir aos cidadãos locais padrões mínimos de atendimento.

\section{0 federalismo municipal assimétrico}

O federalismo brasileiro é caracterizado por uma vocação qualificada de organização simétrica dos municípios, o que conduz ao chamado vício da uniformidade. A diversidade é um traço indissociável do federalismo, por isso, a uniformidade pode matá-lo. Para a realidade da federação, a legislação simétrica é um sonho enganoso e só gera decepções ${ }^{15}$.

No contexto histórico brasileiro, a dicotomia central-local, que aqui emprestamos a esse binômio o sentido de autonomia municipal e simetria legislativa, é uma realidade que se arrasta desde a implantação do federalismo. Já tivemos a oportunidade de conviver com o chamado federalismo nominal, por ocasião do Estado Novo, quando, apesar de a Constituição assegurar que o Brasil era um Estado federal, na prática, vivíamos na condição de Estado unitário. Nessa ocasião prevaleceu apenas o polo central do binômio federativo (central-local). No entanto, o polo apenas local do binômio federativo (central-local) ainda não se teve aqui a oportunidade de experimentar. Ao contrário, a autonomia municipal conferida aos municípios é resultado de ações políticas que remontam ao Brasil-Colônia ${ }^{16}$.

Não obstante, essa vocação uniformizadora, a distribuição de rendas em desarmonia com a distribuição de deveres, tem contribuído para construir a real

\footnotetext{
15 TAVARES, 1937 apud HORTA, Raul Machado. Direito constitucional. 2. ed. rev. atual. e amp. Belo Horizonte: Del Rey, 1999. p. 623.

${ }^{16}$ BAGGIO, Roberta Camineiro. Federalismo no contexto da nova ordem global: perspectivas de (re)formulação da federação brasileira. Curitiba: Juruá, 2006. p. 112.
} 
estrutura de desigualdade que debilita a Federação ${ }^{17}$. É isso que se procura demonstrar adiante.

O federalismo municipal assimétrico brasileiro é marcado por dois aspectos principais, a saber: a) a intensa criação de municípios; e b) o aumento das receitas postas à disposição dos municípios.

Esses dois fatores produziram consequências indesejáveis, tanto do ponto de vista econômico quanto do social que serão explicitadas a seguir. ${ }^{18}$.

Primeira: aumentaram os volumes absoluto e relativo de transferências de receitas tributárias originadas nos municípios grandes para os municípios pequenos, com o provável efeito líquido de desestimular a atividade produtiva realizada nos grandes municípios, sem estimulá-la nos pequenos.

Segunda: beneficiaram a pequena parte (não necessariamente a mais pobre) da população brasileira que vive nos pequenos municípios, ao destinarem mais recursos para as respectivas prefeituras, e prejudicaram a maior parte da mesma população, que habita os outros municípios, cujos recursos se tornaram mais escassos.

Terceira: aumentaram os recursos utilizados no pagamento de despesa com o Legislativo (e, provavelmente, as despesas administrativas em geral, ou seja, os custeios de gabinetes de prefeitos, câmaras de vereadores e administrações municipais), ao mesmo tempo em que reduziram, em termos relativos, o montante de recursos que o setor público (União, estados e municípios) tinha disponível para aplicar em programas sociais e em investimento.

\subsection{Primeiro aspecto: intensa criação de Municípios}

A Tabela 1 mostra que, de 1984 a 1997, foram instalados 1.405 municípios no país, sendo as regiões Sul e Nordeste aquelas com maior contribuição absoluta

${ }^{17}$ MAGALHÃES, José Luiz Quadros. Poder municipal: paradigmas para o estado constitucional brasileiro. Belo Horizonte: Del Rey, 1999. p. 209.

${ }^{18}$ GOMES, Gustavo Maia; MAC DOWELL, Maria Cristina. Descentralização política, federalismo fiscal e criação de municípios: o que é mau para o econômico nem sempre é bom para o social. Brasília: IPEA, 2000. p. 5. (Texto para discussão, n. 706). 
ao processo. Dado que, em 1984, existiam 4.102 municípios no Brasil, conclui-se que, nos 13 anos que vão de 1984 a 1997, o número total de municípios no país aumentou em $34,3 \%$.

Tabela 1 - Brasil e Regiões, Número de Municípios Instalados após 1984, por Estratos de População, 1997.

\begin{tabular}{|c|c|c|c|c|c|c|}
\hline $\begin{array}{c}\text { Grupos de Municípios } \\
\text { - População }\end{array}$ & Nordeste & Norte & $\begin{array}{c}\text { Centro- } \\
\text { Oeste }\end{array}$ & Sul & Sudeste & Brasil \\
\hline Até 5.000 hab. & 146 & 97 & 80 & 296 & 116 & 735 \\
\hline 5.000 a 10.000 hab. & 107 & 49 & 30 & 87 & 87 & 360 \\
\hline $\mathbf{1 0 . 0 0 0}$ a 20.000 hab. & 125 & 42 & 19 & 19 & 29 & 234 \\
\hline $\mathbf{2 0 . 0 0 0}$ a 5.000 hab. & 21 & 18 & 6 & 2 & 14 & 61 \\
\hline 50.000 a 100.000 hab. & 2 & 3 & 3 & 1 & 2 & 11 \\
\hline $\mathbf{1 0 0 . 0 0 0}$ a 500.000 hab. & 1 & - & - & - & 3 & 4 \\
\hline Total & 402 & 209 & 138 & 405 & 251 & 1.405 \\
\hline
\end{tabular}

Fonte: IBGE - Organização do Território e Contagem da População 1996.

A Tabela 1 mostra que, dos 1.405 municípios instalados no Brasil, de 1984 a 1997, nada menos de 1.329 (94,5\%) têm menos de 20 mil habitantes e são considerados pequenos; 1.095 (78\%) desses municípios instalados são muito pequenos; e 735 (32\%) são micromunicípios.

De acordo com dados do IBGE, de 1940 a 1997, a proporção de municípios com até 20 mil habitantes saltou de $54,5 \%$ para $74,8 \%$.

\subsection{Segundo aspecto: aumento de receitas postas a disposição dos Municípios}

A Tabela 2 mostra que apenas 9\% da receita corrente disponível dos municípios de até 5 mil habitantes no Brasil era própria, no sentido de resultar de recursos arrecadados por eles próprios. No intervalo entre 10 mil e 20 mil habitantes, a proporção de receitas próprias sobre receitas correntes totais era ainda muito baixa (12,3\%, em 1996). Os municípios de mais de 1 milhão de habitantes, em contraste, tinham receitas próprias equivalentes a quase $56 \%$ de suas receitas correntes totais, ou seja, para custear suas despesas, os pequenos municípios dependem fortemente das transferências de impostos, especialmente dos impostos federais, via Fundo de 
Participação dos Municípios. Esses impostos não são gerados nos municípios pequenos, mas nos grandes.

Tabela 2 - Brasil e Regiões, Receita Corrente Própria dos Municípios como Percentagem da sua Receita Corrente Total por Grupos de Municípios, 1996.

\begin{tabular}{|l|c|c|c|c|c|c|}
\hline \multicolumn{1}{|c|}{$\begin{array}{c}\text { Grupos de } \\
\text { Municípios - } \\
\text { População }\end{array}$} & Nordeste & Norte & $\begin{array}{c}\text { Centro- } \\
\text { Oeste }\end{array}$ & Sul & Sudeste & Brasil \\
\hline Até 5.000 hab. & 2,9 & 4,4 & 7,5 & 9,9 & 10,1 & 8,9 \\
\hline $\mathbf{5 . 0 0 0}$ a 10.000 hab. & 4,0 & 3,4 & 7,8 & 12,9 & 12,6 & 10,1 \\
\hline $\mathbf{1 0 . 0 0 0}$ a 20.000 hab. & 4,0 & 4,3 & 9,7 & 16,3 & 17,7 & 12,3 \\
\hline $\mathbf{2 0 . 0 0 0}$ a 5.000 hab. & 5,8 & 9,1 & 15,4 & 23,1 & 23,0 & 17,5 \\
\hline $\mathbf{5 0 . 0 0 0}$ a 100.000 hab. & 10,6 & 15,0 & 19,4 & 27,1 & 20,8 & 25,3 \\
\hline $\begin{array}{l}\mathbf{1 0 0 . 0 0 0} \text { a 500.000 } \\
\text { hab. }\end{array}$ & 21,3 & 18,8 & 25,0 & 37,7 & 36,3 & 34,2 \\
\hline $\begin{array}{l}\mathbf{5 0 0 . 0 0 0} \text { a 1.000.000 } \\
\text { hab. }\end{array}$ & 28,1 & - & 47,7 & - & 41,4 & 38,1 \\
\hline $\begin{array}{l}\text { Mais de 1.000.000 } \\
\text { hab }\end{array}$ & 43,6 & 32,3 & 43,4 & 52,5 & $60, .2$ & 55,9 \\
\hline Total & 17,9 & 20,3 & 20,9 & 29,2 & 41,0 & 33,5 \\
\hline
\end{tabular}

Fonte: IBGE - Organização do Território e Contagem da População 1996 e Secretaria do Tesouro Nacional - STN. A Tabela inclui 4.628 municípios para os quais os dados estiveram disponíveis.

As regras de repartição do Fundo de Participação dos Municípios materializam os fluxos líquidos de recursos tributários entre os municípios brasileiros.

Para mostrar isso, são necessários dois tipos de informações. Uma é a distribuição, em 1996, das cotas do FPM por regiões e por grupos de tamanhos da população. A outra é uma estimativa de contribuição de cada grupo de municípios para a formação do FPM. Com essas duas informações, o passo seguinte consistiu, simplesmente, em subtrair do FPM recebido a contribuição do respectivo grupo de municípios para o financiamento daquele fundo. Os grupos de municípios que apresentam resultados positivos nessas operações são, naturalmente, recebedores líquidos dos recursos do FPM; o fato é inverso no caso dos municípios para os quais a mesma operação aritmética apresenta resultado negativo. A Tabela 3 expõe os resultados encontrados. 
Tabela 3 - Brasil e Regiões, FPM Recebido menos Contribuição do Grupo de Municípios para a Formação daquele Fundo por Estratos de População, 1996.

\begin{tabular}{|l|c|c|c|c|c|c|}
\hline $\begin{array}{l}\text { Grupos de } \\
\text { Municípios- } \\
\text { População }\end{array}$ & Nordeste & Norte & $\begin{array}{c}\text { Centro- } \\
\text { Oeste }\end{array}$ & Sul & Sudeste & Brasil \\
\hline $\begin{array}{l}\text { Até 5.000 } \\
\text { hab. }\end{array}$ & 83.556 & 40.269 & 99.136 & 219.898 & 297.895 & 740.755 \\
\hline $\begin{array}{l}\mathbf{5 . 0 0 0} \text { a } \\
\mathbf{1 0 . 0 0 0} \text { hab. }\end{array}$ & 258.669 & 44.765 & 82.565 & 220.151 & 295.471 & 901.624 \\
\hline $\begin{array}{l}\mathbf{1 0 . 0 0 0} \text { a } \\
\mathbf{2 0 . 0 0 0} \text { hab. }\end{array}$ & 663.017 & 50.410 & 113.394 & 264.019 & 375.149 & 1.465 .990 \\
\hline $\begin{array}{l}\mathbf{2 0 . 0 0 0} \text { a } \\
\mathbf{5 . 0 0 0} \text { hab. }\end{array}$ & 679.669 & 84.507 & 100.080 & 168.547 & 391.830 & 1.424 .634 \\
\hline $\begin{array}{l}\mathbf{5 0 . 0 0 0} \text { a } \\
\mathbf{1 0 0 . 0 0 0} \text { hab. }\end{array}$ & 248.141 & 45.271 & 27.229 & 38.337 & 102.566 & 461.546 \\
\hline $\begin{array}{l}\mathbf{1 0 0 . 0 0 0} \text { a } \\
\mathbf{5 0 0 . 0 0 0} \text { hab. }\end{array}$ & 151.910 & 95.789 & 34.485 & -101.015 & -784.566 & -603.396 \\
\hline $\begin{array}{l}\mathbf{5 0 0 . 0 0 0} \text { a } \\
\mathbf{1 . 0 0 0 . 0 0 0} \\
\text { hab. }\end{array}$ & 70.257 & - & - & - & -457.667 & -387.410 \\
\hline $\begin{array}{l}\text { Mais de } \\
\mathbf{1 . 0 0 0 . 0 0 0} \\
\text { hab. }\end{array}$ & -63.905 & -80.850 & -23.407 & -340.510 & -3.495 .079 & -4.003 .744 \\
\hline Total & 2.091 .315 & 280.164 & 433.483 & 469.426 & -3.274 .389 & 0 \\
\hline Font IBGE & & & & & \\
\hline
\end{tabular}

Fonte: IBGE - Organização do Território e Contagem da População 1996. Secretaria do Tesouro Nacional - STN. Secretaria da Receita Federal. A tabela inclui 4.315 municípios.

Em todas as regiões, os megamunicípios (de mais de 1 milhão de habitantes), considerados em conjunto, são financiadores líquidos dos demais. Além disso, no Sudeste e no Sul, também os municípios dos grupos de 100-500 mil e de 500 mil-1 milhão transferem recursos líquidos para os demais.

Da mesma forma, para o Brasil como um todo, os grupos de municípios com mais de 100 mil habitantes financiam (via FPM) os municípios com menos de 100 mil habitantes. 
A última linha da Tabela 3 mostra que, quando as regiões são consideradas, apenas o Sudeste tem resultado negativo (recebe menos do que arrecada), ou seja, o conjunto dos seus municípios contribui para a formação do FPM com mais recursos financeiros do que os recursos que o fundo lhe paga.

Outra consequência importante é que, dentro de suas respectivas regiões (exceto no Sudeste) e no Brasil como um todo, os municípios muito pequenos, especialmente os do grupo com até 5 mil habitantes (micromunicípios), dispõem de mais recursos financeiros per capita do que quaisquer outros. Essa situação ocorre em razão dos recursos federais, repassados pelo FPM, com forte viés favorável aos micromunicípios, que proporcionam a esses sua situação privilegiada.

A Tabela 4 mostra as estimativas da receita corrente total per capita dos municípios, por regiões e por grupos de tamanhos da população, para o ano de 1996. Em praticamente todos os casos, os municípios de menos de 5 mil habitantes são os que têm as maiores disponibilidades de recursos financeiros por habitante. A única exceção é o Sudeste, onde os municípios de mais de 1 milhão de habitantes têm um pouco mais de recursos por habitante do que os de até 5 mil habitantes.

Tabela 4 - Brasil e Regiões, Receita Corrente Total per Capita dos Municípios, por Grupos de Municípios Agregados Segundo a População, 1996.

\begin{tabular}{|l|c|c|c|c|c|c|}
\hline $\begin{array}{c}\text { Grupos de Municípios - } \\
\text { População }\end{array}$ & $\begin{array}{c}\text { Nor- } \\
\text { deste }\end{array}$ & Norte & $\begin{array}{c}\text { Centro- } \\
\text { Oeste }\end{array}$ & Sul & Sudeste & Brasil \\
\hline Até 5.000 hab. & 295,0 & 288,6 & 429,9 & 468,2 & 470,7 & 431,3 \\
\hline 5.000 a 10.000 hab. & 199,3 & 187,5 & 311,6 & 303,4 & 303,1 & 269,4 \\
\hline $\mathbf{1 0 . 0 0 0 ~ a ~ 2 0 . 0 0 0 ~ h a b . ~}$ & 153,0 & 135,9 & 269,4 & 274,0 & 274,0 & 220,2 \\
\hline $\mathbf{2 0 . 0 0 0}$ a 5.000 hab. & 139,0 & 123,2 & 211,8 & 246,5 & 290,4 & 208,3 \\
\hline $\mathbf{5 0 . 0 0 0}$ a 100.000 hab. & 124,3 & 204,1 & 203,8 & 247,8 & 298,7 & 225,0 \\
\hline $\mathbf{1 0 0 . 0 0 0 ~ a ~ 5 0 0 . 0 0 0}$ hab. & 158,2 & 152,4 & 184,2 & 253,6 & 33,1 & 271,4 \\
\hline 500.000 a 1.000.000 hab. & 224,1 & - & 264,4 & - & 365,1 & 307,9 \\
\hline Mais de 1.000.000 hab & 232,9 & 262,5 & 271,9 & 387,1 & 489,9 & 405,8 \\
\hline Total & 167,5 & 190,7 & 244,6 & 283,9 & 366,1 & 281,4 \\
\hline
\end{tabular}

Fonte: IBGE - Organização do Território e Contagem da População 1996 e Secretaria do Tesouro Nacional - STN. A Tabela inclui 4.628 municípios para os quais os dados estiveram disponíveis. 
Os grandes beneficiários dos critérios de repartição de recursos tributários entre os municípios são os pequenos municípios e, dentre estes, especialmente os de 5 mil habitantes. Dessa forma, as populações beneficiárias da descentralização política e do federalismo municipal são as que habitam os pequenos municípios.

A Tabela 5 mostra que apenas 2,2\% da população brasileira vive em micromunicípios. A população se eleva para 7,5\%, se tomarmos todos os municípios com até 10 mil habitantes. Finalmente, menos de 20\% (exatamente 19,6\%) da população brasileira vive em municípios pequenos, ou seja, com populações inferiores a 20 mil habitantes.

Tabela 5 - Brasil e Regiões, Participação Percentual dos Grupos de Municípios na População Total do Brasil, 1996.

\begin{tabular}{|l|c|c|c|c|c|c|}
\hline \multicolumn{1}{|c|}{$\begin{array}{c}\text { Grupos de } \\
\text { Municípios - } \\
\text { População }\end{array}$} & Nordeste & Norte & $\begin{array}{c}\text { Centro- } \\
\text { Oeste }\end{array}$ & Sul & Sudeste & Brasil \\
\hline Até 5.000 hab. & 0,33 & 0,17 & 0,28 & 0,66 & 0,80 & 2,24 \\
\hline $\begin{array}{l}5.000 \text { a 10.000 hab. } \\
1,50\end{array}$ & 0,39 & 0,49 & 1,26 & 1,63 & 5,27 \\
\hline $\begin{array}{l}10.000 \text { a 20.000 hab. } \\
\text { 20.000 a 5.000 hab. }\end{array}$ & 7,50 & 1,68 & 1,08 & 2,54 & 5,17 & 17,97 \\
\hline $\begin{array}{l}50.000 \text { a 100.000 } \\
\text { hab. }\end{array}$ & 3,96 & 1,20 & 0,55 & 2,31 & 4,63 & 12,65 \\
\hline $\begin{array}{l}100.000 \text { a 500.000 } \\
\text { hab. }\end{array}$ & 4,12 & 1,33 & 1,21 & 4,23 & 12,46 & 23,36 \\
\hline $\begin{array}{l}500.000 \text { a } 1.000 .000 \\
\text { hab. }\end{array}$ & 2,48 & - & 0,38 & - & 3,92 & 6,79 \\
\hline $\begin{array}{l}\text { Mais de } 1.000 .000 \\
\text { hab }\end{array}$ & 3,52 & 1,46 & 1,80 & 1,76 & 11,13 & 19,67 \\
\hline Total & 28,50 & 7,19 & 6,68 & 14,97 & 42,65 & 100,00 \\
\hline
\end{tabular}

Fonte: IBGE - Organização do Território e Contagem da População 1996 e Secretaria do Tesouro Nacional - STN. A Tabela inclui 4.628 municípios para os quais os dados estiveram disponíveis.

Um dos mitos da literatura municipal no Brasil é que os municípios menores são aqueles cujas populações são as mais pobres. Os dados mostram outra realidade. 
A Tabela 6 revela que os municípios de até 5 mil habitantes gastaram, em 1996, R\$20,6 reais por habitante para sustentar seus legislativos. Esse valor supera o de qualquer outro grupo de municípios, classificados segundo sua população. Isso significa que menos dinheiro está sobrando, portanto, para o financiamento de investimentos e para a prestação de serviços públicos nos setores de saúde, educação, segurança pública, saneamento e outros.

Tabela 6 - Brasil e Regiões, Gastos com Legislativo Municipal per Capita, 1996.

\begin{tabular}{|l|c|c|c|c|c|c|}
\hline $\begin{array}{c}\text { Grupos de Municípios } \\
\text { - População }\end{array}$ & Nordeste & Norte & $\begin{array}{c}\text { Centro- } \\
\text { Oeste }\end{array}$ & Sul & Sudeste & Brasil \\
\hline Até 5.000 hab. & 18,0 & 22,5 & 26,4 & 19,3 & 20,2 & 20,6 \\
\hline 5.000 a 10.000 hab. & 13,4 & 13,5 & 21,4 & 12,2 & 12,8 & 13,7 \\
\hline 10.000 a 20.000 hab. & 9,2 & 10,4 & 15,7 & 10,4 & 13,1 & 11,0 \\
\hline 20.000 a 5.000 hab. & 8,6 & 8,6 & 12,7 & 9,7 & 13,3 & 10,5 \\
\hline 50.000 a 100.000 hab. & 7,2 & 16,1 & 9,6 & 10,9 & 15,3 & 11,6 \\
\hline 100.000 a 500.000 hab. & 11,5 & 9,7 & 15,4 & 11,4 & 17,2 & 14,7 \\
\hline $\begin{array}{l}500.000 \text { a 1.000.000 } \\
\text { hab. }\end{array}$ & 17,4 & - & 21,4 & - & 16,2 & 16,9 \\
\hline Mais de 1.000.000 hab & 13,5 & 14,8 & 24,5 & 17,9 & 15,5 & 15,6 \\
\hline Total & 10,8 & 12,6 & 16,9 & 12,1 & 15,6 & 13,5 \\
\hline
\end{tabular}

Fonte: IBGE - Organização do Território e Contagem da População 1996 e Secretaria do Tesouro Nacional - STN. A Tabela inclui 4.628 municípios para os quais os dados estiveram disponíveis.

Dada as regras do FPM, um aumento no número de municípios pequenos, sobretudo de micromunicípios, implicará um aumento das transferências dos grandes para os pequenos. Em outras palavras: se existe um bolo tributário igual a 100 para ser rateado entre os municípios e se esse bolo tributário é gerado nos municípios grandes e apropriado por todos os municípios, grosso modo, cada vez que se aumenta o número de pequenos municípios, também aumenta a proporção de recursos tributários apropriados por esses municípios, que contribuem muito pouco para a geração das receitas tributárias redistribuídas. 


\section{A distribuição do poder}

A distribuição constitucional de poderes é o ponto nuclear da noção de Estado Federal. São notórias as dificuldades para saber que matérias devem ser entregues à competência da União, dos Estados e dos Municípios. O princípio geral que norteia a repartição de competências entre os entes federativos é o da predominância do interesse. Assim, cabe à União os temas de interesse geral; aos Estados, os de interesse regional; e aos Municípios, os de interesse local ${ }^{19}$.

A competência legislativa do Município pode ser facilitada com a utilização de quatro regras, a saber: $1 .^{a}$ ) poderes municipais expressos e exclusivos; $2 .^{a}$ ) poderes federais expressos e implícitos e poderes estaduais expressos; $3 .^{\mathrm{a}}$ ) poderes municipais implícitos; e $4 .{ }^{\mathrm{a}}$ ) poderes concorrentes.

A primeira regra afasta qualquer outra competência sobre o assunto, seja ela federal ou estadual, visto que a matéria é de competência expressa e exclusiva do Município. A segunda regra significa que, quando a competência municipal for implícita, prevalecem as competências expressa e implícita, estadual e federal, respectivamente. A terceira regra estabelece que a competência implícita do município afasta a competência estadual remanescente. Por fim, a quarta regra ocorre quando as esferas federal, estadual e municipal disputam a competência. Nesse caso, a ordem de prioridade legislativa segue a mesma ordem, a partir da União ${ }^{20}$.

No entanto, é tarefa complexa discernir os interesses gerais, dos locais ou regionais. A forma de definição da competência do Município foi diversa da utilizada para prever as competências dos Estados e da União. Enquanto para Estados e União foram definidas as matérias a serem objeto de legislação (privativa e concorrente), para os municípios foi prevista uma competência genérica para "legislar sobre assuntos de interesse local" e "suplementar a legislação federal e a estadual no que couber" (art. 30. ${ }^{\circ}$, I e II, CF). Embora a Constituição discrimine algumas competências municipais exclusivas, o ponto central da competência

${ }^{19}$ CORRALO, Giovani da Silva. Município: autonomia na federação brasileira. Curitiba: Juruá, 2006. p. 169.

${ }^{20}$ LEAL, 1954 apud MEIRELLES, Hely Lopes. Direito municipal brasileiro. 14. ed. atual. por Márcio Schneider Reis e Edgard Neves da Silva. São Paulo: Malheiros, 2006. p 133. 
legislativa municipal é dominado pela expressão “assuntos de interesse loca” ${ }^{21}$. É essa a chave hermenêutica para se desvendar a delimitação das competências constitucionais dos municípios ${ }^{22}$. Contudo, deve-se ter em conta que é a predominância e não a exclusividade que deve caracterizar o interesse local, visto que dificilmente exista um interesse local que não seja reflexamente de interesse do Estado e também da União ${ }^{23}$.

Diante dessas considerações expendidas, constata-se que interesse local é um conceito complexo, que só pode ser definido tendo em vista a situação concreta, pois para cada local se terá um rol diferente de assuntos assim classificados. $\mathrm{O}$ assunto de interesse local não é aquele que interessa exclusivamente ao Município, mas aquele que predominantemente afeta à população do lugar. Há assuntos que interessam a todo o país, mas que possuem aspectos que exigem uma regulamentação própria para determinados locais. Daí se dizer que o que caracteriza o interesse local não é a matéria, mas determinadas situações. Aspectos da mesma matéria podem exigir tratamentos diferenciados pela União, pelos Estados e pelos Municípios. O essencial é que não se perca a noção de sistema, verificando-se a compatibilidade entre os diversos diplomas legais e a Constituição.

Não se podem excluir matérias do rol dos temas a serem legislados pelo município. A fórmula utilizada pelo Constituinte de 1988 revela que sempre que prevalecer um interesse do local o Município poderá editar sua própria lei, independentemente de a matéria ter sido atribuída à competência legislativa de outro ente da Federação. Deve, é evidente, ser a norma municipal compatível com as normas já adotadas pela União e pelo Estado, se a estas entidades tiver sido atribuída a competência a respeito da matéria. Se não for possível que a norma municipal trate de matéria definida na Constituição como de competência da União ou dos Estados, desde que não privativa, praticamente se estará anulando a autonomia municipal.

${ }^{21}$ ALMEIDA, Fernanda Dias Menezes. Competências na Constituição de 1988. São Paulo: Atlas, 2002. p. 113.

${ }^{22}$ CORRALO, Giovani da Silva. Município: autonomia na federação brasileira. Curitiba: Juruá, 2006. p. 177.

${ }^{23}$ MEIRELLES, Hely Lopes. Direito municipal brasileiro. 14. ed. atual. por Márcio Schneider Reis e Edgard Neves da Silva. São Paulo: Malheiros, 2006. p. 134 - 135. 
Quanto à competência para suplementar a legislação federal e a estadual, o critério a definir quais as matérias a serem objetos de legislação municipal é a existência ou não de competência administrativa para o Município. A competência para suplementar a legislação das outras unidades existe quando há o dever constitucional de agir em determinada matéria. A atuação do Município necessita, por vezes, de regras específicas, tendo em vista a realidade própria da cidade.

$\mathrm{Na}$ ausência de legislação federal ou estadual sobre determinado tema, o Município poderá tratar exaustivamente da matéria com o objetivo de viabilizar a sua competência material.

\section{Município como ente da federação}

Há quem defenda que a ampliação da autonomia municipal, com a possibilidade de auto-organização pelas Leis Orgânicas, não foi suficiente para posicionar em definitivo o enquadramento do Município na Federação brasileira. Ao lado da autonomia, não se ampliou a participação do Município na federação, deixando-o fora do pacto federativo.

José Nilo de Castro está entre aqueles que não reconhecem o Município como ente federativo. Para ele, a Federação não é de municípios, mas de estados. Os municípios não têm representação no Senado Federal e não participam do processo legislativo para a proposição de emenda à Constituição. Não possuem Poder Judiciário. As suas leis e atos normativos não se submetem ao controle concentrado perante o Supremo Tribunal Federal ${ }^{24}$. Em arrimo ao que defende, ajunta o entendimento semelhante de José Alfredo de Oliveira Baracho ${ }^{25}$. Deve ser consignado, contudo, que a obra desse autor é anterior à promulgação da atual Constituição Brasileira. No entanto, o constitucionalista José Afonso da Silva, já na vigência da Constituição de 1988, também não comunga com a ideia de que os municípios fazem parte da Federação, chegando mesmo a afirmar que a Constituição assim não o diz ${ }^{26}$. Entre os autores

\footnotetext{
${ }^{24}$ CASTRO, José Nilo de. Direito municipal positivo. 6. ed. rev. e atual. Belo Horizonte: Del Rey, 2006. p. 27.

${ }^{25}$ Baracho, 1982 apud CASTRO, José Nilo de. Direito municipal positivo. 6. ed. rev. e atual. Belo Horizonte: Del Rey, 2006. p. 27.

${ }^{26}$ SILVA, José Afonso da. Curso de direito constitucional positivo. 21. ed. São Paulo: Malheiros, 2002. p. 620.
} 
que defendem esse entendimento, além dos já citados, podem ser encontrados Raul Machado Horta ${ }^{27}$, Roque Antônio Carazza ${ }^{28}$ e Pinto Filho ${ }^{29}$.

Contudo, há os que entendem que o ordenamento constitucional assegura ao município o status de ente que compõe a Federação brasileira. Mesmo entendendo tratar-se de algo exótico, visto que o Estado Federal é bidimensional, Augusto Zimmermann ${ }^{30}$ reconhece que o Município integra o sistema federativo tridimensional brasileiro. Hely Lopes Meirelles sempre foi um ardoroso defensor do reconhecimento do Município como ente da Federação, mesmo antes da Constituição Federal de $1988^{31}$. Acrescidos a esses que assim pensam, podem ser citados ainda Alexandre de Moraes $^{32}$, Celso Bastos ${ }^{33}$ e Manoel Gonçalves Ferreira Filho $^{34}$. Segundo o ensinamento de Charles Durand ${ }^{35}$, o Estado federal pressupõe uma autonomia que tem como fundamento dois elementos: a existência de órgãos próprios e um rol de competências exclusivas. Esses dois elementos, é forçoso reconhecer, estão presentes no Município brasileiro por imperativo do comando constitucional.

Neste ponto, cumpre assinalar a existência de uma tendência de valorização dos municípios, mesmo em países em que o Município não é constitucionalmente reconhecido como partícipe da federação. Tal é o caso da Constituição do México que, em seu artigo $115 .^{\circ}$, inciso II, dispõe sobre a realidade municipal, sem, contudo, conferir-lhe o status de ente federativo. Mesmo assim, constitucionalistas daquele país entendem que o Município não é apenas uma forma de descentralização

${ }^{27}$ HORTA, Raul Machado. Repartição de competências na Constituição Federal de 1988. Revista Trimestral de Direito Público, São Paulo, n. 2, p. 11. 1993.

${ }^{28}$ CARAZZA, Roque Antônio. Curso de direito constitucional tributário. São Paulo: Malheiros, 1999. p. 118.

${ }^{29}$ PINTO FILHO, Francisco Bilac. A intervenção federal e o federalismo assimétrico. Rio de Janeiro: Forense, 2002. p. 180.

${ }^{30}$ ZIMMERMANN, Augusto. Teoria geral do federalismo democrático. 2. ed. Rio de Janeiro: Lúmen Júris, 2005. p. 46.

${ }^{31}$ MEIRELLES, Hely Lopes. Direito municipal brasileiro. 14. ed. atual. por Márcio Schneider Reis e Edgard Neves da Silva. São Paulo: Malheiros, 2006. p. 45 - 47.

${ }^{32}$ MORAES, Alexandre. Direito constitucional. São Paulo: Atlas, 2002. p. 273-275.

${ }_{33}$ BASTOS, Celso. A federação no Brasil. Brasília: Instituto dos Advogados de São Paulo, 1985. p. 40.

${ }^{34}$ FERREIRA FILHO, Manoel Gonçalves. Aspectos do direito constitucional contemporâneo. São Paulo: Saraiva, 2003. p. 183.

${ }^{35}$ DURAND, Charles. Federalismo y federalismo europeo. Madrid: Tecnos, 1965. 
administrativa. Ao revés, advogam que essa perspectiva teórica está ultrapassada, visto que não é uma parte do Poder Executivo e nem dele deriva. O Município nasce da vontade do povo, como uma forma de organização política, sendo, portanto, a pedra angular do novo federalismo que surge como uma exigência social na Revolução mexicana ${ }^{36}$. Pedro M. Martinez ${ }^{37}$ tem defendido um alargamento da autonomia municipal no México. Segundo ele, o Município equilibra o poder hegemônico com o poder do cidadão, sendo assim uma escola de democracia, em que os cidadãos podem participar do desenvolvimento e bem-estar coletivo. Nesse contexto, defende o autor que autonomia municipal é dispor de representação política, poder de participação, de governo, bem como dotação de recursos necessários para alcançar os fins almejados. Nessa linha de raciocínio, defende ainda o chamado novo federalismo mexicano, que consiste na divisão de poderes entre o Executivo, o Legislativo e o Judiciário, e de funções fiscais entre os distintos níveis de governo dentro de um Estado-Nação.

O mesmo vem ocorrendo no ambiente doutrinário da Argentina, onde se defende a autonomia dos municípios em uma modalidade plena e semiplena e também a divisão dos municípios em categorias, sendo uns de primeira e outros de segunda categoria, tudo, porém, caminhando na direção de sedimentar o $\mathrm{Mu}$ nicípio como ente político. Segundo defende Antonio M. Hernández ${ }^{38}$, não se pode conceber uma cidade, sede do ser humano, que, segundo Aristóteles, é um animal político, que careça de poder, de governo e de política.

No caso brasileiro, o art. $1 .^{\circ}$ da atual Constituição do Brasil assegura, pelo menos, três realidades inegáveis que são de interesse para o assunto aqui em foco. Em primeiro plano, o dispositivo é categórico em asseverar que o seu conteúdo

\footnotetext{
${ }^{36}$ MARTÍNEZ, Reynaldo Robles. Función legislativa del município, Biblioteca Jurídica Virtual. Instituto de Investigaciones Jurídicas. El município em México y em el mundo: Primer Congreso Internacional de Derecho Municipal, 2005, p. 436 - 437.

${ }^{37}$ MARTINEZ, Pedro M. El município: descentralización y democracia - elementos para a la (re)construcción del federalismo em México. Disponível em: <www.azc. uam.mx/ publicaciones/gestion/num5/doc11>.

${ }^{38}$ HERNÁNDEZ, Antonio M. As leis orgânicas municipais como instrumentos para garantizar la autonomia y mejorar lãs formas de gobierno y administración local. Caso argentino, Biblioteca Jurídica Virtual. Instituto de Investigaciones Jurídicas. El município em México y em el mundo: Primer Congreso Internacional de Derecho Municipal, 2005, p. 120, 144, 150.
} 
se refere à República Federativa do Brasil. Trata-se, pois, indubitavelmente de uma Federação. Em seguida, assegura o texto constitucional que essa Federação é formada da união dos Estados, Municípios e do Distrito Federal. Portanto, os municípios encontram-se inseridos na estrutura tridimensional do federalismo brasileiro. Por fim, colhe-se ainda desse artigo que essa formação federativa é indissolúvel, como que a dizer: a desconsideração do Município como partícipe da Federação, compromete o federalismo brasileiro, na forma preconizada pela Constituição Federal.

\section{Conclusão}

Desnecessário é o exame profundo para verificar que, no contexto das Constituições brasileiras, a começar da de 1891, que implantou constitucionalmente o sistema federativo, até a promulgação da Constituição Federal de 1988, o Município tem ocupado lugar de destaque no quadro estrutural do Estado brasileiro. As oscilações, tendo como órgão central, ora o Estado, ora a União, não foram suficientes para impedir que o Poder Constituinte de 1988 lhe assegurasse significativa autonomia e, também, o status de ente participante do sistema federativo brasileiro.

O ponto de equilíbrio entre centralização e descentralização, igualdade e diversidade, não tem sido uma tarefa bem sucedida no Estado Federal brasileiro. Embora esses institutos - centralização, descentralização, igualdade e diversidade - sejam ínsitos ao federalismo, a questão relevante, então, passa a ser quem os promove. A proposta do sistema teórico federal parece ser que o ente federativo seja o protagonista de sua própria história, indicando, ele mesmo, o seu próprio grau ou nível de centralização, descentralização, igualdade ou diversidade que pretende para a sua trajetória. Entre nós, no entanto, os poderes centrais, União e Estados, conforme o caso, têm sido os guardiães desses institutos, pondo-se como autores dos destinos dos entes federados de níveis inferiores, contrariando, assim, a proposta teórica federativa. Conforme restou demonstrado no capítulo que trata do federalismo municipal assimétrico, a tentativa de igualdade levada a efeito por meio do Fundo de Participação dos Municípios produziu resultado de desigualdade, de assimetria, e não de igualdade ou simetria. 
Embora a Constituição Federal de 1988 tenha alargado o campo de autonomia dos municípios, tendo como referência os textos constitucionais anteriores, o fato é que, no campo da competência legislativa, precisa-se de alguma melhora. A dubiedade da expressão "assunto de interesse local", grafada no inciso I do art. $30 .^{\circ}$ da Constituição Federal, associada com a natureza centralizadora do federalismo brasileiro, tem impedido o desenvolvimento do Município nessa área, que é tão relevante para sedimentar a sua autonomia.

O certo é que, hoje, o Município está constitucionalmente consagrado como um partícipe do sistema federativo brasileiro, despontando-se, assim, como um sistema federal genuíno.

\section{Federal state and municipal power}

\section{Abstract}

The aim of this paper is to analyze the issue of autonomy of the municipality in the Brazilian federal system. For discharging from this goal, the text is structured in four chapters. It starts with the overview of the development of the municipality in the context of Brazilian to go into the analysis of the consequences of the Municipal Participation Found for local symmetry and the distribution of powers under the Constitution coming into doctrinal disagreement over the participation of municipality in the federal legislation in order to conclude that notwithstanding the Constitution of 1988 has extended the scope of autonomy of municipalities, the uncertainty of the expression "subject of local interest" associated with the centralized nature of Brazilian federalism has prevented the development of the municipalities in this area, which is so important to solidify their autonomy.

Keywords: Municipal. Municipal federalism. Power distribution.

\section{Referências}

AFFONSO, Rui. Os municípios e os desafios da federação no Brasil. Fundação SEADE, [S.1], v. 10, n. 3, 1996. 
ALMEIDA, Fernanda Dias Menezes. Competências na Constituição de 1988. São Paulo: Atlas, 2002.

BAGGIO, Roberta Camineiro. Federalismo no contexto da nova ordem global: perspectivas de (re)formulação da federação brasileira. Curitiba: Juruá, 2006.

BASTOS, Celso. A federação no Brasil. Brasília: Instituto dos Advogados de São Paulo, 1985.

BRASIL. Supremo Tribunal Federal. Representação no 95. Tribunal Pleno. Relator: Min. Cândido Mota Filho. Brasília, 02 de setembro de 1957. Disponível em: <www.stf.gov.br>.

BRASIL. Supremo Tribunal Federal. Representação no 314. Tribunal Pleno. Relator: Min. Lafayette de Andrada. Brasília, 23 de setembro de 1957. Disponível em: <www.stf.gov.br>.

BRASIL. Supremo Tribunal Federal. Representação no 350. Tribunal Pleno. Relator: Min. Henrique D’Avila. Brasília, 26 de janeiro de 1959. Disponível em: <www.stf. gov.br>.

CARAZZA, Roque Antônio. Curso de direito constitucional tributário. São Paulo: Malheiros, 1999.

CASTRO, José Nilo de. Direito municipal positivo. 6. ed. rev. e atual. Belo Horizonte: Del Rey, 2006.

CORRALO, Giovani da Silva. Município: autonomia na federação brasileira. Curitiba: Juruá, 2006.

DURAND, Charles. Federalismo y federalismo europeo. Madrid: Tecnos, 1965.

GOMES, Gustavo Maia; MAC DOWELL, Maria Cristina. Descentralização política, federalismo fiscal e criação de municípios: o que é mau para o econômico nem sempre é bom para o social. Brasília: IPEA, 2000.

HERNÁNDEZ, Antonio M. As leis orgânicas municipais como instrumentos para garantizar la autonomia y mejorar las formas de gobierno y administración local. Caso Argentino. Biblioteca Jurídica Virtual. Instituto de Investigaciones Jurídicas. El município em México y em el mundo: Primer Congreso Internacional de Derecho Municipal, 2005, p. 120, 144 e 150. 
HERRERA, Oscar Rebolledo. El marco jurídico del município en un contexto federalizado. Biblioteca Jurídica Virtual. Instituto de Investigaciones Jurídicas. El município em México y en el mundo. In: CONGRESO INTERNACIONAL DE DERECHO MUNICIPAL, 1., 2005, p. 380 - 381.

HORTA, Raul Machado. Direito constitucional. 2. ed. rev. atual. e amp. Belo Horizonte: Del Rey, 1999.

HORTA, Raul Machado. Repartição de competências na Constituição Federal. Revista Trimestral de Direito Público, São Paulo, n. 2, p. 11, 1993.

MAGALHÃES, José Luiz Quadros. Poder municipal: paradigmas para o estado constitucional brasileiro. Belo Horizonte: Del Rey, 1999.

MARTINEZ, Pedro M. El município: descentralización y democracia - elementos para a la (re)construcción del federalismo em México. Disponível em: <www.azc. uam.mx/publicaciones/gestion/num5/doc11>.

MARTINEZ, Reynaldo Robles. Función legislativa del município. Biblioteca Jurídica Virtual. Instituto de Investigaciones Jurídicas. El município em México y em el mundo: Primer Congreso Internacional de Derecho Municipal, 2005.

MEIRELLES, Hely Lopes. Direito municipal brasileiro. 14. ed. atual. por Márcio Schneider Reis e Edgard Neves da Silva. São Paulo: Malheiros, 2006.

MORAES, Alexandre. Direito constitucional. São Paulo: Atlas, 2002.

PINTO FILHO, Francisco Bilac. A intervenção federal e o federalismo assimétrico. Rio de Janeiro: Forense, 2002.

SILVA, José Afonso da. Curso de direito constitucional positivo. 21. ed. São Paulo: Malheiros, 2002.

TOCQUEVILLE, Aléxis de. A democracia na América. Tradução de Eduardo Brandão. São Paulo: M. Fontes, 2005. Livro 1.

ZIMMERMANN, Augusto. Teoria geral do federalismo democrático. 2. ed. Rio de Janeiro: Lúmen Júris, 2005. 